\title{
Miniaturization of Two-Photon Microscopy for Imaging in Freely Moving Animals
}

\author{
Fritjof Helmchen, Winfried Denk, and Jason N.D. Kerr
}

\begin{abstract}
This article describes the development and application of miniaturized two-photon-excited fluorescence microscopes ("two-photon fiberscopes"). Two-photon fiberscopes have been developed with the aim of enabling high-resolution imaging of neural activity in freely behaving animals. They use fiber optics to deliver laser light for two-photon excitation. Their small front piece typically contains a miniature scanning mechanism and imaging optics. Two-photon fiberscopes can be made sufficiently small and lightweight to be carried by rats and mice and to allow virtually unrestricted movement within a behavioral arena. Typically mounted to the animal's skull above a cranial window, two-photon fiberscopes permit imaging of cells down to at least $250 \mu \mathrm{m}$ below the brain surface (e.g., in rat neocortex). In freely exploring animals, action-potential-evoked calcium transients can be imaged in individual somata of visual cortex neurons bulk-labeled with a calcium indicator. Two-photon fiberscopes thus enable high-resolution optical recording of neural activity with cellular resolution during natural behaviors.
\end{abstract}

Two-photon microscopy is highly suitable for imaging in intact tissue and in living animals owing to its reduced susceptibility to light scattering. In neuroscience, two-photon imaging has opened a new field for in vivo optical measurements of neural dynamics on the subcellular, cellular, and local population levels (for reviews, see Helmchen and Denk 2005; Kerr and Denk 2008; Grewe and Helmchen 2009; Wallace and Kerr 2010). Two-photon calcium imaging has, for example, been applied to study the functional organization of neuronal populations in primary areas of the somatosensory (Kerr et al. 2007; Sato et al. 2007), visual (Ohki et al. 2005; Mrsic-Flogel et al. 2007; Greenberg et al. 2008), and auditory cortices (Rothschild et al. 2010) as well as in the cerebellar cortex (Sullivan et al. 2005; Nimmerjahn et al. 2009).

Under anesthesia, brain state and neural dynamics are, of course, altered and it is unclear exactly how these changes affect the animal's perception. The need to work in anesthetized animals is, therefore, a major limitation and it is desirable, perhaps essential, to ultimately perform experiments in awake, behaving animals. In recent years, a number of approaches have emerged that enable optical recordings with cellular resolution in awake, behaving animals, and two main avenues have been followed.

- In the first approach, animals are trained to accept head fixation. An awake animal can then be placed under a standard two-photon microscope and imaging is performed as during anesthesia (Dombeck et al. 2007; Greenberg et al. 2008). The advantage of this approach is that a regular microscope can be used; the main disadvantages are that the behavior repertoire is constrained and extensive training is necessary.

Adapted from Imaging in Neuroscience (ed. Helmchen and Konnerth). CSHL Press, Cold Spring Harbor, NY, USA, 2011.

(C) 2013 Cold Spring Harbor Laboratory Press

Cite this article as Cold Spring Harb Protoc; 2013; doi:10.1101/pdb.top078147 
- The second approach, which is the focus of this article, is to fiber-couple and miniaturize the microscope front piece so that it can be carried by a rat (Helmchen et al. 2001) or even a mouse (Flusberg et al. 2005b). The benefit of this approach is that animal behavior is far less restricted and it is possible to obtain high-resolution optical recordings during behavioral experiments, very much like chronic electrophysiological recordings in rodents. The difficulty with this approach lies in the special optical design. Miniaturization has to be achieved while maintaining sufficient sensitivity and resolution to measure calcium signals in individual neurons and neuronal processes in the brain.

In this article, we first survey the different technologies that have been explored during recent years for miniaturization of two-photon microscopy and introduce the key technological challenges. We then discuss some applications of two-photon fiberscopes, including the recent demonstration of calcium measurements with single-cell resolution in the visual cortex of freely moving rats (Sawinski et al. 2009).

IMAGING SETUP

Equipment

To build a two-photon fiberscope, several key components are the same as those required for a standard two-photon microscope. Hence, a fiberscope can be built as an addition to an existing setup. In the excitation pathway, an ultrafast laser source providing $\sim 100$-fsec laser pulses in the 700- to 1050-nm wavelength range is required. Typically, a tunable commercial Ti:sapphire laser system is used, although a custom-built laser may provide certain advantages (Sawinski and Denk 2007). For efficient two-photon excitation, a laser with large maximal output power is preferable because light guidance through optical fibers involves power losses, and fluorescence excitation is further reduced by pulse distortions caused by dispersion and nonlinearities (see below). Further standard components required include an intensity controller and a telescope for laser beam size adjustment. Specific to the fiberscope is a fiber coupler to stably and efficiently couple the excitation light into the single-mode optical fiber. If fluorescence is collected through a large-core fiber and detected at the fiber end remote from the front piece of the two-photon fiberscope, a standard detector system can be used. Besides these standard components, special technology is required for building a miniaturized front piece (see below). A list of useful components is given in Table 1.

\section{Considerations for Two-Photon Fiberscope Design}

First, mobilization of the microscope requires delivery of the excitation light via an optical fiber, through which it is difficult to maintain short pulse widths at high powers as is needed for efficient two-photon excitation. Second, a miniaturized scanning device is needed to scan the output beam from the optical fiber. Third, to focus the scanned beam, a small water-immersion objective suitable for imaging in the living brain is required. Fourth, fluorescence needs to be efficiently collected and detected, either directly at the fiberscope front piece using a small photodetector or with a remote detector following guidance through a large-core collection fiber (Fig. 1A-C). Finally, a simple and flexible mounting mechanism should permit easy fixation and removal of the fiberscope onto the animal's head. In the following sections, we provide some details about these various technological aspects. Further information can be found in several reviews (Helmchen 2002; Flusberg et al. 2005a) and in the original papers cited below.

\section{Two-Photon Excitation through Optical Fibers}

The standard optical fibers for delivering laser light are step-index single-mode fibers, that is, solid glass fibers with a small $(\sim 5-\mu \mathrm{m}$ diameter $)$ core of slightly higher refractive index. In these optical 
F. Helmchen et al.

TABLE 1. Components useful for designing a two-photon fiberscope

\begin{tabular}{|c|c|c|}
\hline Component & Specifications & Model (vendors) \\
\hline Single-mode fiber & $\begin{array}{l}\text { Core size 5-6 } \mu \mathrm{m} \text {; NA 0.12-0.15; cladding diameter } \\
\quad 125 \mu \mathrm{m}\end{array}$ & F-SF, F-SPF (Newport); FS-SN-4224 (3M) \\
\hline $\begin{array}{l}\text { Hollow-core photonic crystal } \\
\text { fiber }\end{array}$ & $\begin{array}{l}\text { Air core } 9 \mu \mathrm{m} \text {; zero-dispersion wavelength } 812 \mathrm{~nm} \text {; } \\
\quad \text { NA } 0.12-0.15 \text {; cladding diameter } 125 \mu \mathrm{m}\end{array}$ & HC-800-01 (NKT Photonics, Denmark) \\
\hline Piezoelectric elements & Benders ( $\sim 2 \mathrm{~mm} \times 8 \mathrm{~mm}$ in size); tubes, etc. & $\begin{array}{l}\text { (EDO; Polytec Pl; Morgan Matroc; Piezo Systems; } \\
\text { Argillon) }\end{array}$ \\
\hline \multirow[t]{2}{*}{ Tube lens } & Aspheric (NA 0.15) & C280TM, C260TM (Geltech lenses; Thorlabs) \\
\hline & Achromat $(f=12.7 \mathrm{~mm})$ & LAKN22-SFL6 (Thorlabs) \\
\hline Long-pass dichroic & Cold mirror or dichroic beam splitter & M43-960 (Edmund Optics) \\
\hline Short-pass dichroic & $\begin{array}{l}\text { Hot mirror, near-infrared blocking filter, or dichroic } \\
\text { beam splitter }\end{array}$ & Calflex X (Linos Photonics) \\
\hline Objective & $\begin{array}{l}\text { Water immersion; NA }>0.8 \text {; large fluorescence } \\
\text { collection field of view }\end{array}$ & $\begin{array}{l}\text { Custom design (Throl Optical Systems) (modified from } \\
\text { design by Syncotec; now defunct) }\end{array}$ \\
\hline Collection lens & Small lens; NA matched to collection fiber & For example, C230TM (Geltech lens; Thorlabs) \\
\hline Fluorescence collection fiber & $\begin{array}{l}\text { Large core } 0.6-1 \mathrm{~mm} \text {; high transmission at visible } \\
\text { wavelengths; high NA }\end{array}$ & $\begin{array}{l}\text { FT-600-URT (Thorlabs); MO2-534 (Edmund Optics); } \\
\text { plastic fiber PJUFB1000 (Toray Deutschland) }\end{array}$ \\
\hline $\begin{array}{l}\text { Small photomultiplier tube } \\
\text { (front piece detection) }\end{array}$ & $\begin{array}{l}\text { High quantum efficiency at visible wavelengths; } \\
\text { weight } 4 \mathrm{~g}\end{array}$ & R7400U (Hamamatsu) \\
\hline Small DC motor & Weight 300 mg; gear ratio 1:125 & Smoovy motor (Micro Precision Systems) \\
\hline Position-sensitive detector (PSD) & $\begin{array}{l}\text { Two-dimensional silicone-based detector with } \\
\text { several milliliters side length }\end{array}$ & 2L10SP (ON-TRAK Photonics); S5991 (Hamamatsu) \\
\hline
\end{tabular}

NA, numerical aperture.

fibers, ultrafast laser pulses broaden because of material dispersion and also, at the high laser powers required for deep imaging, because of nonlinear effects (Agrawal 1995). Such broadening limits the efficiency of two-photon excitation and therefore has to be reduced to a minimum. It is possible to compensate for dispersion-induced broadening by giving the short-wavelength components a sufficient head start (a negative "prechirp") so that blue and red components arrive at the fiber end at the same time. Prechirping the laser pulses can be accomplished before coupling to the fiber with a pair of diffraction gratings (Treacy 1969) or with prism sequences (Walmsley et al. 2001; Sawinski and Denk 2007). For example, two reflection gratings ( 400 grooves $/ \mathrm{mm}$ and $9.7^{\circ}$ blaze angle; Richardson Grating Laboratory) in double-pass configuration provide around $-60,000 \mathrm{fsec}^{2}$ at $17-\mathrm{cm}$ spacing, compensating for $\sim 1.5 \mathrm{~m}$ of optical fiber (Helmchen et al. 2001). The optimal spacing between gratings (or prisms) can be found by measuring the pulse width after the fiber with an autocorrelator and adjusting the spacing for minimal pulse width. Even with prechirping, however, laser pulses progressively broaden at increasing power levels because of nonlinear optical effects in the fiber core (mainly self-phase modulation; Agrawal 1995). Nonlinear pulse broadening becomes substantial starting at surprisingly low average powers $(\sim 10 \mathrm{~mW})$ and is dominant at the high average power levels needed for imaging deep into tissue (Helmchen et al. 2002). As a result, relatively long laser pulses $(\sim 1$ psec or longer) are used in effect at high excitation powers when standard step-index fibers are used, resulting in suboptimal two-photon excitation.

Several approaches have been devised to alleviate the problem of nonlinear pulse broadening. For example, large-core specialty fibers (Helmchen et al. 2002; Ouzounov et al. 2002) as well as spectral and temporal shaping of the input pulse (Clark et al. 2001) have been tested but are not widely used. The problem of pulse broadening can be nearly completely circumvented by using hollow-core photonic crystal fibers (Göbel et al. 2004b). In these fibers, most of the laser light travels through an air-filled core and thus encounters little dispersion or nonlinearity, minimizing pulse broadening even at high average power (Göbel et al. 2004b). No prechirping is required and the laser beam can be coupled straight into the fiber. Photonic crystal fibers have been successfully used in a number of twophoton fiberscope designs (Flusberg et al. 2005b; Engelbrecht et al. 2008; Piyawattanametha et al. 2009). A disadvantage is, however, their susceptibility to contamination of the fiber tip, probably attributable to the intricate photonic crystal structure, which poses a particular problem when the fiber end is integrated into a fiber scanner device and thus cannot be easily recleaved. 


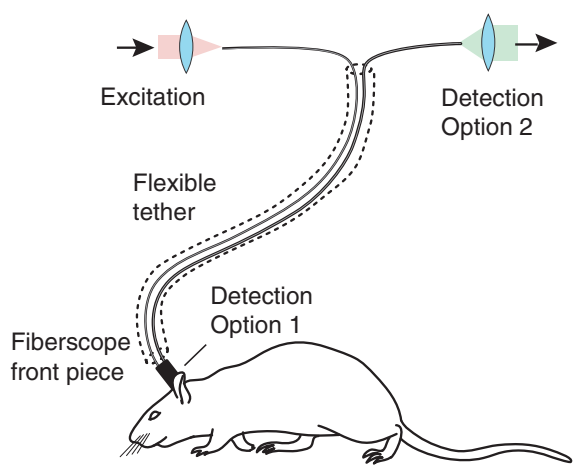

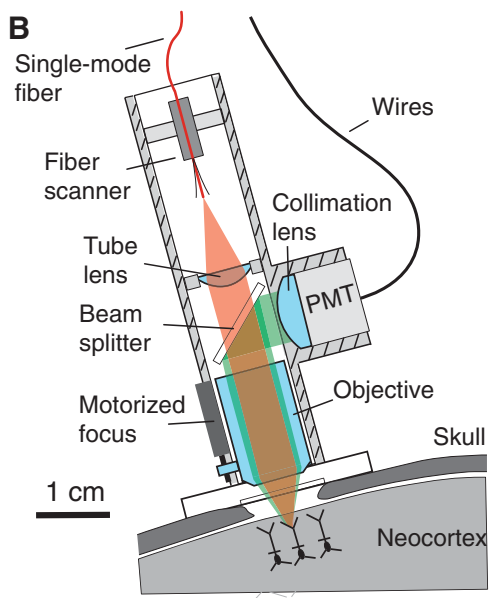

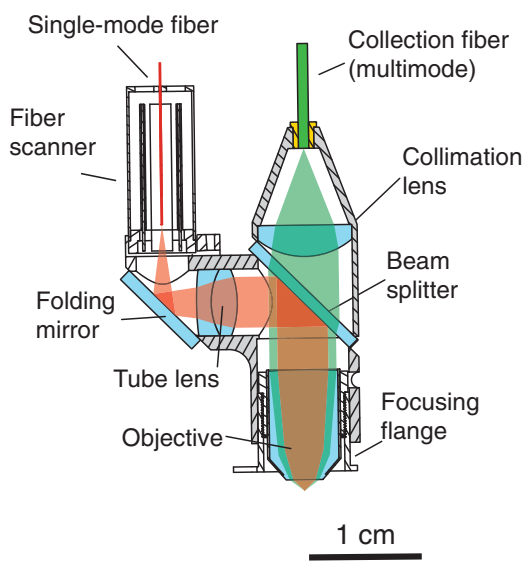

E

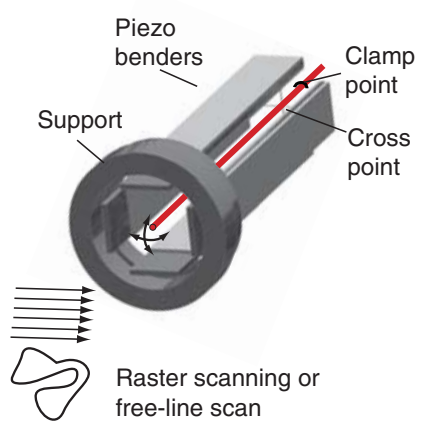

$\mathbf{F}$
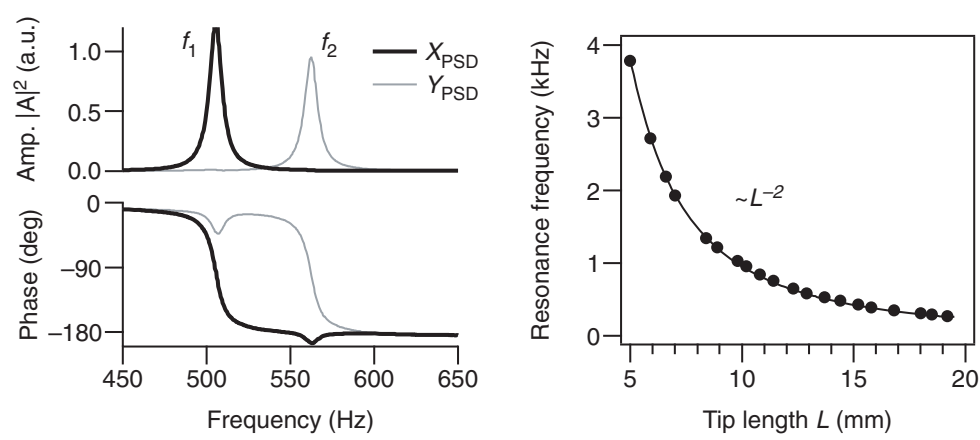

FIGURE 1. (A) Two-photon fiberscope setup. Excitation light is delivered through fiber optics to a miniaturized microscope front piece that is attached to the head of a freely behaving animal. Two principle options for fluorescence detection are indicated. $(B)$ Example for Option 1: Original design used by Helmchen et al. (2001). Excitation light is guided through a single-mode fiber. Scanning is achieved using resonant mechanical vibration of the fiber tip. Nearinfrared excitation light (red) is passed through a long-pass dichroic beam splitter and fluorescent light (green) is detected by a small photomultiplier tube (PMT) at the front piece. (C) Example for Option 2: Recent design used by Sawinski et al. (2009). A nonresonant fiber scanner is used and near-infrared excitation light is collimated and deflected by a short-pass dichroic beam splitter. Fluorescence is collected through a large-core multimode fiber and detected remotely. $(D)$ Resonant fiber scanning. (Left) Resonant vibration along a line is induced by driving a single piezoelectric bender, to which the fiber is glued, near the resonance frequency $\left(f_{\text {res }}\right)$. (Middle) Two-dimensional Lissajous scanning. Stiffening of the fiber end in one direction splits the resonance frequency in $f_{X}$ and $f_{Y}$. Simultaneous excitation of vibrations in $x$ and $y$ directions creates a Lissajous pattern, more or less homogeneously covering an area. (Right) Spiral scanning. A piezo tube with quadrant electrodes induces spiral scanning by driving $x$ and $y$ directions at the same resonance frequency but with a $90^{\circ}$ phase shift. $(E)$ Nonresonant fiber scanner. This "piezolever fiber scanner" achieves fiber tip deflections by leveraging the movements of two crossed pairs of piezo benders. The fiber is glued to the tips of the cross-connected piezo pairs at the cross point close to the clamped fiber base. Driving the piezo benders with sawtooth-like waveforms (fast and slow) at frequencies below the resonance frequency creates raster scanning similar to conventional two-photon microscopes. Offset voltages to the $x$ and $y$ piezo benders provide the unique option to shift the scanned field laterally. Moreover, free-line scanning is possible. $(F)$ Fiber resonance characteristics. (Left) Resonance curves measured with a position-sensitive detector (PSD) for a fiber tip stiffened in one direction. Note the distinct resonance peaks for $x$ and $y$ directions. (Right) Resonance frequency of a $125-\mu \mathrm{m}$ diameter single-mode fiber as a function of the free length of the fiber end. 
F. Helmchen et al.

\section{Miniaturized Fiber-Scanning Devices}

A compact scanning device is essential for miniaturization. One possibility is to move the tip of the illuminating fiber, which is positioned in an optical plane conjugate to the focal plane (Giniunas et al. 1991). In this approach, the output light beam emerging from the fiber core is collimated and then refocused to a focal spot using small optics (see below), so that any movement of the fiber tip translates into a lateral movement of the focal spot. Multiple options exist for how to move the fiber tip. In particular, we need to distinguish resonant and nonresonant scanning (Fig. 1D,E). We first discuss several ways to exploit resonant vibration before describing a nonresonant fiber-scanning method.

Resonant mechanical vibration of a free-standing fiber end can be easily induced with a piezoelectric bending element ("piezo bender"). The bare fiber (with the coating stripped off) is glued to the piezo bender so that $10-20 \mathrm{~mm}$ of the fiber end remains free to vibrate (Fig. 1D). For a $125-\mu \mathrm{m}$ (standard) diameter fiber, this results in a resonance frequency $f_{\text {res }}$ ranging from 200 to $1000 \mathrm{~Hz}$ (Fig. 1F). In general, for transverse vibration of a cylindrical rod, $f_{\text {res }}$ is given by the equation

$$
f_{\text {res }}=\frac{s_{0}^{2}}{4 \pi} \frac{R}{L^{2}} \sqrt{\frac{E}{\rho}},
$$

where $R$ is the radius, $L$ is the length of the rod, $\rho$ is the density $\left(\sim 2.3 \mathrm{~g} / \mathrm{cm}^{3}\right), E$ is the elasticity module of the fiber ( $\sim 75 \mathrm{GPa})$, and $s_{0}=1.875$ (Bishop and Johnson 1960). Thus, $f_{\text {res }}$ depends inversely on the square of the length $L$ (Fig. 1F).

Two-dimensional Lissajous scanning can be achieved by stiffening the fiber end in one direction with a short $(2-4 \mathrm{~mm}$ ) piece of bare fiber glued to the lower edge of the piezo and to the fiber at $\sim 2-$ to 3-mm distance from the piezo (Fig. 1D). This approach results in two distinct resonance frequencies of the fiber tip, as becomes apparent by driving the piezo with a sinusoidal waveform that is swept in frequency (Fig. 1F). Because the resonance widths are typically only $5-10 \mathrm{~Hz}$, one has to sweep the frequency slowly and finely enough not to miss the resonance. For accurate measurement of the resonance curve, the fiber tip can be imaged onto a two-dimensional position-sensitive detector. When the piezo bender is driven with a superposition of two sine waves at the respective resonance frequencies for the different directions, a Lissajous scan pattern is produced, which has been used in several two-photon fiberscope implementations (Helmchen et al. 2001; Flusberg et al. 2005b). With up to $100-\mathrm{V}$ (peak-to-peak) drive amplitude, resonant vibrations of $>1$-mm peak-to-peak amplitude can be reached and the Lissajous scan pattern can be tuned so that a rectangular area is covered rather homogenously (for details on scan parameters and data acquisition, see Helmchen et al. 2001).

An alternative method of resonant fiber scanning is spiral scanning (Fig. 1D). Here, the fiber is glued inside a piezoelectric tube with quadrant electrodes that enable independent excitation of vibration in $x$ and $y$ directions (Seibel and Smithwick 2002; for review, see Lee et al. 2010). The advantage of spiral scanning is that two-dimensional scanning is easily achieved without stiffening of the fiber end by driving vibrations in the two orthogonal directions with a $90^{\circ}$ phase shift (Fig. 1D). Because small piezo tubes are sufficient to drive fiber vibration, spiral scanners can be made very compact, probably smaller than is possible for Lissajous scanners. For example, in combination with a small gradient-index (GRIN) lens system, a miniature fiberscope front piece $(<1 \mathrm{~g})$ can be realized (Engelbrecht et al. 2008). Moreover, using a short fiber end with a correspondingly high resonance frequency of a few $\mathrm{kHz}$, frame scanning at video rate is possible.

Resonant scanning lacks flexibility and, in particular, does not support lateral offsets or random access scanning. To overcome these limitations, a nonresonant, leverage-based fiber scanner has been developed (Fig. 1E) (Sawinski and Denk 2007). Here, the fiber end is deflected near its clamped base with the help of piezo benders. Because of the leverage, small deflections of the piezo benders are transduced into relatively large fiber tip deflections. Operating below the resonance frequency of the fiber tip, this design permits raster-like scanning of an area, similar to standard galvanometric scan mirrors. It also allows one to randomly access scan points within a field of view, which might be useful 
in future optogenetic applications. This type of scanner was used recently to measure calcium signals in individual neurons of neocortex at $\sim 15 \mathrm{~Hz}$ frame rate in freely behaving rats (Sawinski et al. 2009).

Instead of deflecting the fiber tip, the beam can be scanned using a microelectromechanical system (MEMS), whereby a two-dimensional scanning mirror (Piyawattanametha et al. 2006) is inserted between the fiber end and miniature objective. The use of a coherent fiber bundle avoids scanning in the front piece at all (Göbel et al. 2004a). None of these methods, however, has become widely adopted and currently fiber tip scanning appears to provide the best results for two-photon excitation.

\section{Small Microscope Objectives}

For high-resolution in vivo imaging, a water-immersion objective with a numerical aperture (NA) of $\geq 0.8$ is desirable. Standard high-quality microscope objectives are too large and too heavy to be useful for microscope miniaturization. Thus, the first two-photon fiberscope took advantage of a waterimmersion objective, in which the core part could be removed and reassembled in a minimal holder (Helmchen et al. 2001). This type of objective is not available anymore. In the more recent fiberscope design shown in Figure 1C, a specially designed water-immersion objective with NA 0.9 (Throl Optical Systems) was used (Sawinski et al. 2009). As an alternative, GRIN lens systems have been used in two-photon fiberscopes, typically with limited NA $(0.48-0.58)$ of the front GRIN lens (Flusberg et al. 2005b; Engelbrecht et al. 2008; Piyawattanametha et al. 2009). The recent development of thin compound lens systems, made of a GRIN lens and a planoconvex lens, now enables NA values up to 0.85 (Barretto et al. 2009). These new lens systems should be highly suitable for two-photon fiberscope designs.

\section{Fluorescence Detection}

In principle, there are two options for fluorescence collection: (1) to detect fluorescence light directly at the fiberscope head piece and (2) to collect and guide it through an additional optical fiber and then project it onto a remote detector (Fig. 1A-C). The advantage of the first approach is its simplicity and the high detection efficiency. In the first fiberscope design (Helmchen et al. 2001), a small photomultiplier was used, but in the future a small avalanche photodiode array might provide superior quantum efficiency. The disadvantage here is that more weight is added to the animal's head. Moreover, depending on the design of the photomultiplier tube, high voltages can be present close to the animal. Collecting fluorescence through a large-core fiber suffers from some transmission losses but has the great advantage of being very flexible at the remote end of the collection fiber (Fig. 1C). Any highly sensitive detector can be used irrespective of its size and weight, and the fluorescence light can be separated into multiple spectral windows for multichannel imaging of several fluorescent dyes. As only a small coupling lens is required in the front piece, this detection scheme also helps to further reduce the size and weight of the fiberscope.

\section{Mechanical Attachment to the Animal}

Three issues arise when designing a suitable head-mounting system for the fiberscope: (1) The microscope must be easily detachable; (2) when attached, the microscope must be mechanically stable, even during high-acceleration movements (jerks) of the head; and (3) attachment must not affect the animal's behavior or viability. The second point is especially important when using a raster scan, spiral scan, or free-line scan approach, in which the presumed positions of the beam are used to reconstruct images. Although offline movement correction has been successfully applied (Dombeck et al. 2007; Greenberg et al. 2008), there is a limit as to how much movement can be corrected (Greenberg and Kerr 2009). The attachment system that has been successfully applied to the freely moving animal is based on a two-part system in which the headplate remains permanently bonded to the animal's skull and the fiberscope can be attached (Sawinski and Denk 2007; Sawinski et al. 2009). When the fiberscope is not attached, it should be replaced with a protective cover that protects the cranial window from mechanical damage, such as from the animal's paws during grooming. For the 
F. Helmchen et al.

stable attachment of the headplate to the skull, we prefer using ultraviolet-cured bonding agents rather than bone screws, especially in younger animals in which the skull is thin. Another important consideration is whether it is easily possible to attach and detach the microscope to and from an awake animal while keeping handling of the animal at a minimum. This last point is important for trained animals in which excessive handling can interfere with their behavioral performance (Stüttgen and Schwarz 2008).

\section{FLUORESCENT DYE LABELING IN VIVO}

Imaging with a two-photon fiberscope depends on in vivo fluorescence labeling. Tail-vein injection of a fluorescent dye was used for the first demonstration of two-photon fiberscope imaging in freely moving rats (Helmchen et al. 2001). For imaging neural activity, various methods of labeling neurons can be applied. Individual neurons can be filled with organic indicator dyes via intracellular recording electrodes (high-resistance sharp electrodes; Svoboda et al. 1997) or whole-cell patch pipettes (Helmchen and Waters 2002). This approach has been used for fiberscope measurements of dendritic calcium signals during anesthesia (Helmchen et al. 2001) (Fig. 2A,B). Single-cell labeling is, however, laborious and restricted to small numbers of neurons. When the activity in a larger number of neurons is to be sampled in parallel, population labeling techniques are needed. What has proven popular for fiberscope and fixed-scope experiments is the in vivo loading of populations of neocortical cells with calcium indicators by the local application of membrane-permeant dye (Stosiek et al. 2003). Alternatively, local electroporation of calcium indicator dyes has been used (Nagayama et al. 2007). The use of genetically encoded calcium indicators is also highly promising (Wallace et al. 2008; Tian et al. 2009; Lütcke et al. 2010). The latter approach allows permanent labeling and should, therefore, permit repeated measurements of the same neuronal population in multiple imaging sessions over days, weeks, and perhaps even throughout an animal's life.

\section{EXAMPLES OF APPLICATION}

Using the first Lissajous-type scanning two-photon fiberscope (Helmchen et al. 2001), pyramidal neurons in neocortical layer 2/3 (loaded with calcium indicator via an intracellular electrode) could be resolved in head-restrained, anesthetized rats (Fig. 2A). Using a line-scan mode, with fiber-end vibration induced along one direction, dendritic calcium transients were resolved following intracellular current injection, providing proof-of-concept for the sensitivity of fiberscope calcium measurements (Fig. 2B). As the first awake demonstration, fluorescently labeled blood capillaries were imaged in freely moving rats (Fig. 2C), showing that stable images can be acquired in unrestrained animals, except during periods of strong head movements (Helmchen et al. 2001).

Despite the development of various two-photon fiberscope designs during the past decade (e.g., Flusberg et al. 2005b; Engelbrecht et al. 2008; Piyawattanametha et al. 2009), the original goal of enabling functional measurements of neural activity in freely moving animals remained elusive until recently when a light, compact fiberscope $(\sim 5 \mathrm{~g})$ using a leverage-based fiber scanner was combined with bulk-loading of the visual cortex with calcium-sensitive indicator (Sawinski et al. 2009). This study succeeded in recording spike-evoked calcium transients from animals freely exploring a novel environment that contained static visual stimuli (Fig. 2D-H). Intrinsic optical imaging through the thinned skull can be used to coarsely map the cortical responses. Using the pial blood vessel pattern as a reference, this approach allows placement of the craniotomy without the need to map responses again. To decrease the stress to the animal while attaching the microscope, animals were trained over many days to tolerate repeated handling and head-fixing while awake. Once animals were trained, they were head-fixed, the calcium-sensitive indicator was injected in the area of the cortex previously mapped with intrinsic optical imaging, and the fiberscope was attached. After a calcium 


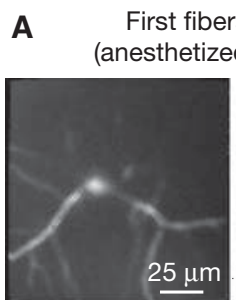

D New fiberscope
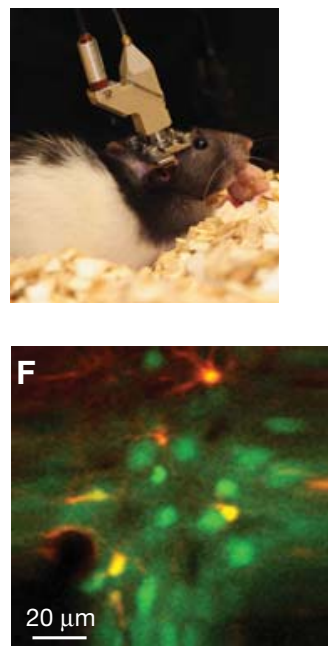

G

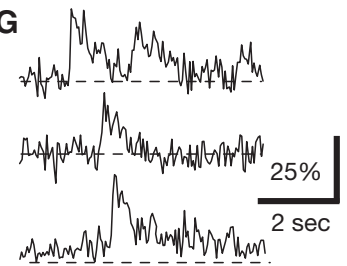

B

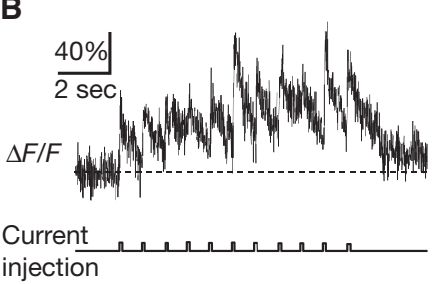

E
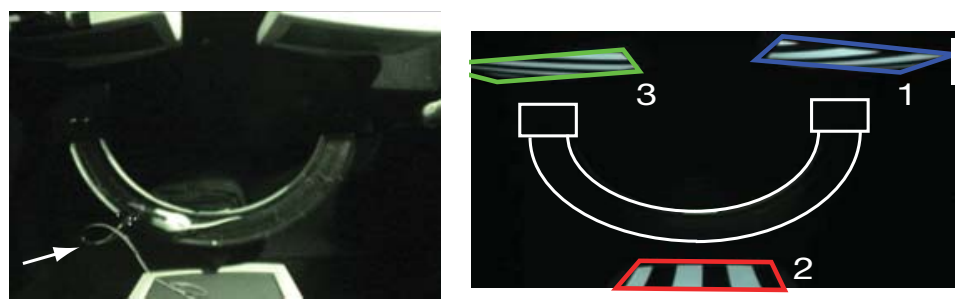

H

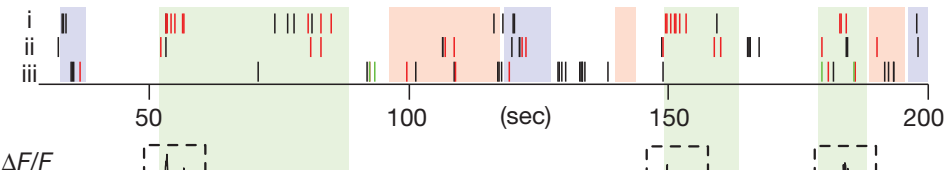

sFF

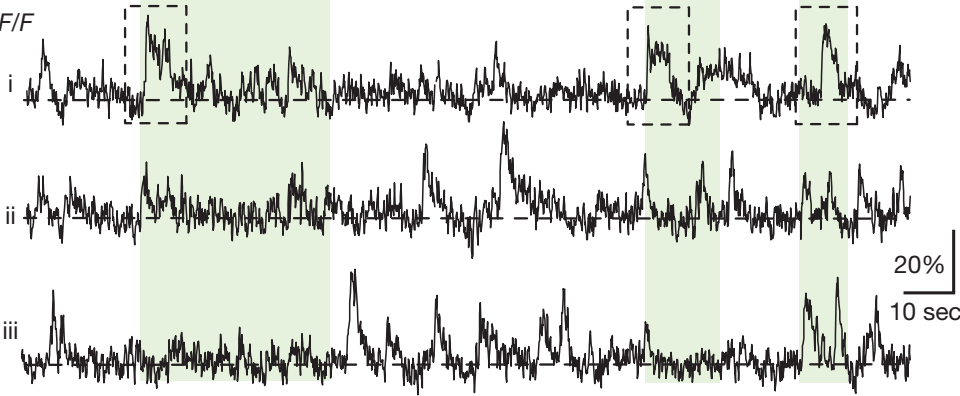

FIGURE 2. Applications of two-photon fiberscope. (A) In vivo images of Calcium Green-1-loaded neocortical layer 2/3 neurons acquired with the first two-photon fiberscope in a head-fixed anesthetized rat using Lissajous-type scanning (Helmchen et al. 2001). (B) Dendritic calcium transients evoked by somatic current injections measured with the fiberscope in line-scan mode. (C) Imaging in freely moving rats. Images show blood vessels stained by tail-vein injection of a fluorescent dye and were obtained in freely moving awake rats using the first two-photon fiberscope (Helmchen et al. 2001). Based on the diameter of capillaries $(\sim 5-6 \mu \mathrm{m})$, we estimate the fields of view to be $\sim 85$ and $\sim 65 \mu \mathrm{m}$ for the left and right image, respectively. $(D-H)$ Two-photon fiberscope imaging with a piezolever fiber scanner in rat visual cortex (Sawinski et al. 2009). (D) Photograph showing the mounted fiberscope. (E) The rat was free to move on an elevated running track (left, top-view photograph; right, schematic diagram) flanked by three video monitors displaying stationary gratings at three different orientations (denoted by blue, red, and green outlines). Arrow in left panel indicates flexible tether containing fiber optics and electrical wires. $(F)$ Fiberscope image of a neuronal population in layer $2 / 3$ stained with the calcium-sensitive indicator Oregon-Green BAPTA-1 (green). Astrocytes were counterstained with sulforhodamine 101 (orange). (G) Typical action potential-evoked calcium transients recorded from neuronal somata with a fast rise, peak, and slow decay to baseline. $(H)$ Examples of raster plots (top) and calcium transients (bottom) showing activity in three neurons (i-iii) during $\sim 5$ min of continuous imaging while the animal was freely exploring the elevated track (black lines correspond to single action potentials, red to doubles, and green to triples). Periods during which the animal's gaze moved across one of the three monitors are indicated by the blocks of background color (color coding shown in $E$ ). Note multiple large transients (dashed boxes in traces) in neuron $\mathrm{i}$ in response to viewing the same monitor (indicated in green) multiple times. For details on raster plot generation, see Greenberg et al. (2008).

indicator-loaded neuronal population $(\sim 10-20$ neurons) had been located, the animal was released onto the running track (a semicircular track raised $\sim 1.5 \mathrm{~m}$ above the ground), which restricted the area the animal could explore while being always fully visible for overhead and side-on cameras that were used to track the animal's position (Fig. 2E). In addition, this setup allowed the unrestricted movement of the fibers and wires attached to the fiberscope. 
F. Helmchen et al.

Full-frame $(64 \times 64$-pixel $)$ images were then acquired at $\sim 10 \mathrm{~Hz}$ while the animal was free to explore a novel environment. This environment included three cathode ray tube monitors, each with a static grating orientated at $-45^{\circ}, 0^{\circ}$, or $45^{\circ}$ (Fig. 2E). Using an overhead camera and four infrared light-emitting diodes attached to the fiberscope, the head of the animal could be accurately tracked in three dimensions. Movement within the two-photon frames was corrected offline and calcium transients were detected (Fig. 2G; Greenberg and Kerr 2009). Calcium transients could then be related to the head position of the animal. The relative orientation and distance to the animal's head were calculated for each screen by using video frames from the video camera, and related to the receptive field of the imaged cortical region (Fig. 2H). A subpopulation of neurons was found to become significantly more active when one specific monitor was in the receptive field, compared with other monitors (Fig. 2H). This fiberscope application shows that neuronal activity can be recorded in a freely behaving animal that is free to interact with a stimulus in a self-determined way.

DISCUSSION

During the past few years, optical fibers have been increasingly used to measure neural activity in mobile animals, mainly in connection with fluorescent calcium indicators. In the simplest case, an optical fiber provides a bulk readout of the mean calcium signal in a local population of neurons (Adelsberger et al. 2005; Murayama et al. 2007; Lütcke et al. 2010). Achieving cellular resolution with small, portable fiberscopes is much more difficult, not only because of the technical challenges associated with miniaturization but also because of strong light scattering in neural tissue. Even though calcium transients in Purkinje cell dendrites of the cerebellum could be imaged in mobile mice using single-photon imaging through a fiber bundle (Flusberg et al. 2008), single-photon approaches are highly susceptible to light scattering and are thus applicable only when the cells of interest are located near the tissue surface. In contrast, two-photon fiberscopes exploit the well-known two-photon advantages, in particular enhanced depth penetration and intrinsic optical sectioning. In principle, it should be possible to reach imaging depths of $\geq 400 \mu \mathrm{m}$ with two-photon fiberscopes, similar to standard two-photon microscopes.

With the demonstration of cellular calcium imaging in freely behaving rats (Sawinski et al. 2009), the application of two-photon fiberscopes has now entered a new phase. Many potential application and further developments can be envisaged. The expression of genetically encoded sensors in transgenic animals or following viral gene delivery will enable long-term measurements from specific, wellidentified ensembles of neurons. This method has the potential to directly relate changes in neural population dynamics to behavioral changes, such as an improved performance in a behavioral task. The fiberscope also will allow the study of social interactions as well as tasks in which the animal needs to be free to move within its environment. Although the two-photon fiberscopes discussed here first of all enable imaging studies in accessible regions such as the neocortex and the cerebellum, the use of GRIN lenses as front objectives or relay lenses (Flusberg et al. 2005b, 2008) should permit functional imaging in deeper brain regions, such as the hippocampus or the basal ganglia. Finally, another fascinating possibility is the combination of two-photon fiberscopes with optogenetic tools to eventually achieve optical control of small cell groups or even of individual neurons in freely behaving animals.

\section{REFERENCES}

Adelsberger H, Garaschuk O, Konnerth A. 2005. Cortical calcium waves in resting newborn mice. Nat Neurosci 8: 988-990.

Agrawal GP. 1995. Nonlinear fiber optics. Academic Press, San Diego.

Barretto RP, Messerschmidt B, Schnitzer MJ. 2009. In vivo fluorescence imaging with high-resolution microlenses. Nat Methods 6: 511512.

Bishop RED, Johnson DC. 1960. The mechanics of vibration. Cambridge University Press, Cambridge.
Clark SW, Ilday FÖ, Wise FW. 2001. Fiber delivery of femtosecond pulses from a Ti:sapphire laser. Opt Lett 26: 1320-1322.

Dombeck DA, Khabbaz AN, Collman F, Adelman TL, Tank DW. 2007. Imaging large-scale neural activity with cellular resolution in awake, mobile mice. Neuron 56: 43-57.

Engelbrecht CJ, Johnston RS, Seibel EJ, Helmchen F. 2008. Ultra-compact fiber-optic two-photon microscope for functional fluorescence imaging in vivo. Opt Express 16: 5556-5564. 
Flusberg BA, Cocker ED, Piyawattanametha W, Jung JC, Cheung ELM Schnitzer MJ. 2005a. Fiber-optic fluorescence imaging. Nat Methods 2: 941-950

Flusberg BA, Lung JC, Cocker ED, Anderson EP, Schnitzer MJ. 2005b. In vivo brain imaging using a portable 3.9 gram two-photon fluorescence microendoscope. Opt Lett 30: 2272-2274.

Flusberg BA, Nimmerjahn A, Cocker ED, Mukamel EA, Barretto RP, Ko TH, Burns LD, Jung JC, Schnitzer MJ. 2008. High-speed, miniaturized fluorescence microscopy in freely moving mice. Nat Methods 5: 935-938.

Giniunas L, Juskaitis R, Shatalin SV. 1991. Scanning fibre-optic microscope. Electronics Lett 27: 724-726.

Göbel W, Kerr JND, Nimmerjahn A, Helmchen F. 2004a. Miniaturized twophoton microscope based on a flexible coherent fiber bundle and a gradient-index lens objective. Opt Lett 29: 2521-2523.

Göbel W, Nimmerjahn A, Helmchen F. 2004b. Distortion-free delivery of nanojoule femtosecond pulses from a Ti:sapphire laser through a hollow-core photonic crystal fiber. Opt Lett 29: 1285-1287.

Greenberg DS, Kerr JND. 2009. Automated correction of fast motion artifacts for two-photon imaging of awake animals. J Neurosci Methods 176: 1-15.

Greenberg DS, Houweling AR, Kerr JND. 2008. Population imaging of ongoing neuronal activity in the visual cortex of awake rats. Nat Neurosci 11: 749-751.

Grewe BF, Helmchen F. 2009. Optical probing of neuronal ensemble activity. Curr Opin Neurobiol 19: 520-529.

Helmchen F. 2002. Miniaturization of fluorescence microscopes using fibre optics. Exp Physiol 87: 737-745.

Helmchen F, Denk W. 2005. Deep tissue two-photon microscopy. Nat Methods 2: 932-940.

Helmchen F, Waters J. 2002. $\mathrm{Ca}^{2+}$ imaging in the mammalian brain in vivo. Eur J Pharmacol 447: 119-129.

Helmchen F, Fee MS, Tank DW, Denk W. 2001. A miniature head-mounted two-photon microscope: High-resolution brain imaging in freely moving animals. Neuron 31: 903-912.

Helmchen F, Tank DW, Denk W. 2002. Enhanced two-photon excitation through optical fiber by single-mode propagation in a large core. Appl Opt 41: 2930-2934.

Kerr JND, Denk W. 2008. Imaging in vivo: Watching the brain in action. Nat Rev Neurosci 9: 195-205.

Kerr JND, de Kock CPJ, Greenberg DS, Bruno RM, Sakmann B, Helmchen F. 2007. Spatial organization of neuronal population responses in layer 2/3 of rat barrel cortex. J Neurosci 27: 13316-13328.

Lee CM, Engelbrecht CJ, Soper TD, Helmchen F, Seibel EJ. 2010. Scanning fiber endoscopy with highly flexible, $1 \mathrm{~mm}$ catheterscopes for widefield, full-color imaging. J Biophotonics 3: 385-407.

Lütcke H, Murayama M, Hahn T, Margolis DJ, Astori S, Meyer zum Alten Borgloh S, Göbel W, Yang Y, Tang W, Kügler S, et al. 2010. Optical recording of neuronal activity with a genetically-encoded calcium indicator in anesthetized and freely moving mice. Front Neural Circuits 4: 9.

Mrsic-Flogel TD, Hofer SB, Ohki K, Reid RC, Bonhoeffer T, Hubener M. 2007. Homeostatic regulation of eye-specific responses in visual cortex during ocular dominance plasticity. Neuron 54: 961-972.

Murayama M, Perez-Garci E, Luscher HR, Larkum ME. 2007. Fiberoptic system for recording dendritic calcium signals in layer 5 neocortical pyramidal cells in freely moving rats. J Neurophysiol 98: 1791-1805.
Nagayama S, Zeng S, Xiong W, Fletcher ML, Masurkar AV, Davis DJ, Pieribone VA, Chen WR. 2007. In vivo simultaneous tracing and $\mathrm{Ca}^{2+}$ imaging of local neuronal circuits. Neuron 53: 789-803.

Nimmerjahn A, Mukamel EA, Schnitzer MJ. 2009. Motor behavior activates Bergmann glial networks. Neuron 62: 400-412.

Ohki K, Chung S, Ch'ng YH, Kara P, Reid RC. 2005. Functional imaging with cellular resolution reveals precise microarchitecture in visual cortex. Nature 433: 597-603.

Ouzounov DG, Moll KD, Foster MA, Zipfel WR, Webb WW, Gaeta AL. 2002. Delivery of nanojoule femtosecond pulses through large-core microstructured fibers. Opt Lett 27: 1513-1515.

Piyawattanametha W, Barretto RPJ, Ko TH, Flusberg BA, Cocker ED, Ra HJ, Lee DS, Solgaard O, Schnitzer MJ. 2006. Fast-scanning two-photon fluorescence imaging based on a microelectromechanical systems twodimensional scanning mirror. Opt Lett 31: 2018-2020.

Piyawattanametha W, Cocker ED, Burns LD, Barretto RP, Jung JC, Ra H, Solgaard O, Schnitzer MJ. 2009. In vivo brain imaging using a portable $2.9 \mathrm{~g}$ two-photon microscope based on a microelectromechanical systems scanning mirror. Opt Lett 34: 2309-2311.

Rothschild G, Nelken I, Mizrahi A. 2010. Functional organization and population dynamics in the mouse primary auditory cortex. Nat Neurosci 13: $353-360$

Sato TR, Gray NW, Mainen ZF, Svoboda K. 2007. The functional microarchitecture of the mouse barrel cortex. PLoS Biol 5: e189.

Sawinski J, Denk W. 2007. Miniature random-access fiber scanner for in vivo multiphoton imaging. J Appl Phys 102: 034701.

Sawinski J, Wallace DJ, Greenberg DS, Grossmann S, Denk W, Kerr JND. 2009. Visually evoked activity in cortical cells imaged in freely moving animals. Proc Natl Acad Sci 106: 19557-19562.

Seibel EJ, Smithwick QYJ. 2002. Unique features of optical scanning, single fiber endoscopy. Lasers Surg Med 30: 177-183.

Stosiek C, Garaschuk O, Holthoff K, Konnerth A. 2003. In vivo two-photon calcium imaging of neuronal networks. Proc Natl Acad Sci 100: 73197324.

Stüttgen MC, Schwarz C. 2008. Psychophysical and neurometric detection performance under stimulus uncertainty. Nat Neurosci 11: 1091-1099.

Sullivan MR, Nimmerjahn A, Sarkisov DV, Helmchen F, Wang SS. 2005. In vivo calcium imaging of circuit activity in cerebellar cortex. J Neurophysiol 94: 1636-1644.

Svoboda K, Denk W, Kleinfeld D, Tank DW. 1997. In vivo dendritic calcium dynamics in neocortical pyramidal neurons. Nature 385: 161-165.

Tian L, Hires SA, Mao T, Huber D, Chiappe ME, Chalasani SH, Petreanu L, Akerboom J, McKinney SA, Schreiter ER, et al. 2009. Imaging neural activity in worms, flies and mice with improved GCaMP calcium indicators. Nat Methods 6: 875-881.

Treacy EB. 1969. Optical pulse compression with diffraction gratings. IEEE J Quantum Electron 5: 454-458.

Wallace DJ, Kerr JN. 2010. Chasing the cell assembly. Curr Opin Neurobiol 20: $296-305$

Wallace DJ, Meyer zum Alten Borgloh S, Astori S, Yang Y, Bausen M, Kugler S, Palmer AE, Tsien RY, Sprengel R, Kerr JND, et al. 2008. Single-spike detection in vitro and in vivo with a genetic $\mathrm{Ca}^{2+}$ sensor. Nat Methods 5: 797-804.

Walmsley I, Waxer L, Dorrer C. 2001. The role of dispersion in ultrafast optics. Rev Sci Instrum 72: 1-29. 


\section{Miniaturization of Two-Photon Microscopy for Imaging in Freely Moving Animals}

Fritjof Helmchen, Winfried Denk and Jason N.D. Kerr

Cold Spring Harb Protoc; doi: 10.1101/pdb.top078147

\begin{tabular}{cc}
$\begin{array}{c}\text { Email Alerting } \\
\text { Service }\end{array}$ & Receive free email alerts when new articles cite this article - click here. \\
\hline $\begin{array}{c}\text { Subject } \\
\text { Categories }\end{array}$ & $\begin{array}{c}\text { Browse articles on similar topics from Cold Spring Harbor Protocols. } \\
\text { Calcium Imaging (116 articles) } \\
\text { Imaging for Neuroscience (342 articles) } \\
\text { Imaging/Microscopy, general (579 articles) } \\
\text { In Vivo Imaging (334 articles) } \\
\text { In Vivo Imaging, general (168 articles) } \\
\text { Labeling for Imaging (339 articles) } \\
\text { Multi-Photon Microscopy (103 articles) }\end{array}$ \\
\hline
\end{tabular}

